\title{
Urinary Excretory Pattern of DDS in Leprosy Patients *
}

\author{
R. GANAPATI \\ Research Officer \\ S. S. NAIK \\ Research Assistant \\ Acworth Leprosy Hospital, Wadala, Bombay 31
}

Selection of diamino diphenyl sulphone (DDS) as the drug of choice for leprosy is validated by experience for over a decade, but its intolerance in a significant proportion of patients and its apparent failure to meet the challenge of $M$. leprae in some patients makes further investigations necessary in these 2 directions. Pettit, Rees and Ridley (1966) claim to have demonstrated the phenomenon of drug resistance in 9 patients in one of the largest in-patient leprosaria in the world, in Malaysia.

In the Acworth Leprosy Hospital when promin was the first sulphone tried it was noted that some patients did not improve. Such patients were found to be excreting the drug rapidly. An increase of the dose resulted in satisfactory improvement. Thus was engendered the concept in the Acworth Leprosy Hospital that the rate of excretion of sulphones had some correlation with improvement.

In recent years 2 patients were encountered in which a satisfactory response could be obtained after raising the dose of DDS to 150 and $200 \mathrm{mgm}$. dailyt (i.e., 0.9 and $1.2 \mathrm{gm}$. per week).

Patient No. 1: B.M.P.

Hindu, male, aged 19 years. Type: Reactional Tuberculoid.

Treated on routine dosages of dapsone for 2 years. At the end of this period during which mild reactions occurred twice, increase in the number of lesions was noted and the patient continued to remain bacteriologically positive for acid fast bacilli. It was found that he was excreting $55.14 \mathrm{mg}$. DDS during 24 hours following an oral test dose of $100 \mathrm{mgm}$., the test being performed after stopping DDS treatment till the urine was free from even a trace of
DDS. The dose was increased gradually from 100 mgm. to $200 \mathrm{mgm}$. daily for 6 days per week. After 3 months of treatment with $150 \mathrm{mgm}$. daily marked improvement was observed and later he became negative for bacilli on the $200 \mathrm{mgm}$. dose.

Patient No. 2: S.M.

Hindu, male, aged 29 years. Type: Tuberculoid Major.

Treated on routine dosage for 5 years. The only lesion on left knee persisted without showing any appreciable change. The DDS excretion test revealed that he was excreting $55.1 \mathrm{mgm}$. out of the $100 \mathrm{mgm}$. test dose. The dose was increased gradually to $150 \mathrm{mgm}$. Nine months after the dose was raised the lesion had definitely flattened and at the end of one year only faint hypopigmentation could be seen.

Improvement noticed with high dose treatment in a few patients prompted us to study the rate of excretion and blood concentration of DDS in different subjects after a test dose.

\section{MATERIAL AND METHODS}

Two hundred patients (182 males and 18 females) of ages ranging from 12 to 65 years attending the Acworth Leprosy Hospital, Wadala, were the subjects for the study. Only patients without evident kidney disease were selected. The types of leprosy from which these patients were suffering were as follows:-

* Paper read at the Seminar conducted under the auspices of the Indian Association of Leprologists at the Central Leprosy Teaching and Research Institute, Chingleput on 10th February, 1968.

$\uparrow$ Routine dose schedule followed in the Acworth Leprosy Hospital, Wadala: $25 \mathrm{mgm}$. daily for 6 days per week for 3 months, increased by $25 \mathrm{mgm}$. (daily for 6 days per week) every 3 months till the maximum of $100 \mathrm{mgm}$. daily for 6 days per week is reached. 
TABLE I

\begin{tabular}{lc}
\hline \multicolumn{1}{c}{ Type } & No. of Patients \\
\hline Tuberculoid & 63 \\
Intermediate & 56 \\
Lepromatous & $8 !$ \\
\hline Total & 200 \\
\hline
\end{tabular}

Before investigation routine anti-leprosy treatment was stopped in all patients for varying periods till the urine did not show even a trace of DDS. The minimum number of days after which no DDS was found was 10 days and the maximum 30 days.

After an oral test dose of $100 \mathrm{mgm}$. of DDS the quantity of total diazotizable material excreted during the subsequent 24 hours was estimated in all the patients by the method described by Simpson (1949) (calorimetric estimation of the coupled compound of diazotized sulphone with $\mathrm{N}$ 1-naphthyl ethylene diaminedihydrochloride). The estimations were made on a Klett-Summerson Photoelectric calorimeter.

Blood concentration of the drug at $2,4,6,8$ and 24 hours after the administration of the drug was studied in 47 patients.
The urinary excretion pattern of 16 patients was studied by repeating the test at intervals of one month, 3 months, and 12 or 14 months.

The wcight of the patients was not taken into consideration, though we feel that the dose in relation to the weight should be an important factor to be considered in future investigations.

RESULTS

TABLE 2

Showing 24-hour urinary excretory pattern following oral test dose of $100 \mathrm{mgm}$. DDS

\begin{tabular}{cc}
\hline $\begin{array}{c}\text { Mgm. of DDS } \\
\text { excreted in } 24 \text { hours }\end{array}$ & $\begin{array}{c}\text { No. of } \\
\text { Patients }\end{array}$ \\
\hline $10-20$ & 1 \\
$2(0-30$ & 13 \\
$30-35$ & 19 \\
$35-40$ & 37 \\
$40-45$ & 35 \\
$45-50$ & 28 \\
$5(0-55$ & 29 \\
$55-60$ & 15 \\
$60-70$ & 16 \\
$70-80$ & 5 \\
$80-90$ & 2 \\
\hline Total & 200 \\
\hline
\end{tabular}

TABLE 3

Showing 24-hour urinary excretion of DDS in $\mathrm{mg} \mathrm{m}$. on repeated testing of patients after 1 month, 3 months and 12 or 14 months

\begin{tabular}{|c|c|c|c|c|c|c|}
\hline \multirow{2}{*}{ Sr. No. } & \multirow{2}{*}{ Patients } & \multicolumn{4}{|c|}{ Excretion Test } & \multirow{2}{*}{$\begin{array}{l}\text { Range of } \\
\text { Difference }\end{array}$} \\
\hline & & Initial & After 1 month & After 3 months & After 12 or 14 months & \\
\hline 1 & J.S. & 34.14 & 29.68 & 27.54 & 41.24 & 13.70 \\
\hline 2 & J.D. & 45.80 & 50.29 & 49.50 & 53.16 & 7.36 \\
\hline 3 & S.N. & 33.28 & 30.63 & 43.46 & 25.71 & 17.75 \\
\hline 4 & M.R. & 51. 76 & 61.53 & - & 53.16 & 9.77 \\
\hline 5 & A.R.MI. & 44.64 & - & 49.65 & - & 5.01 \\
\hline 6 & A.R. & 28.82 & 20.46 & 26.73 & - & 8.36 \\
\hline 7 & V.B. & 66.61 & 45.80 & 57.50 & 46.35 & 20.81 \\
\hline 8 & M.V. & 36.88 & 27.38 & - & 32.60 & 9.50 \\
\hline 9 & N.K. & 37.99 & & - & 48.63 & 10.64 \\
\hline 10 & G.K. & 48.61 & - & 58.04 & - & 9.43 \\
\hline 11 & O.K. & 23.93 & - & - & 32.52 & 8.59 \\
\hline 12 & T.A. & 48.49 & - & - & 47.53 & 0.96 \\
\hline 13 & W.M. & 49.93 & 42.08 & & - & 7.85 \\
\hline 14 & L.G. & 60.43 & - & 65.32 & - & 4.89 \\
\hline 15 & N.G. & 39.25 & - & - & 31.61 & 7.64 \\
\hline 16 & K.N. & 50.04 & - & - & 52.96 & 2.92 \\
\hline
\end{tabular}




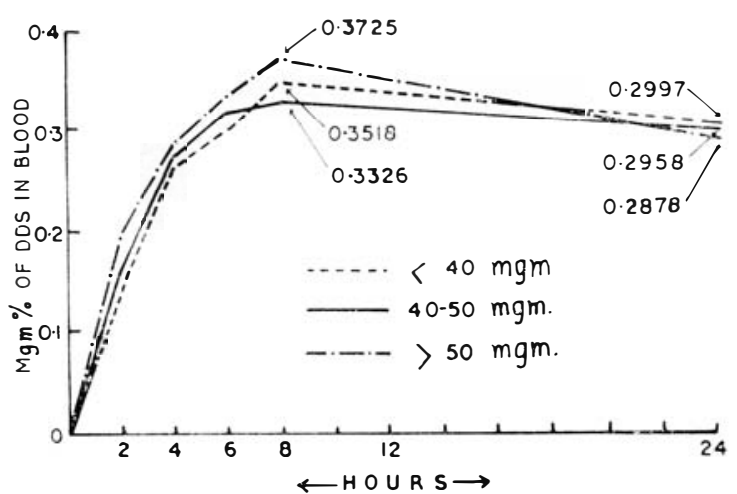

GRAPH 1

Showing blood concentration curves following oral test dose of DDS.

The average of the range of difference is $9.07 \mathrm{mgm}$. which is within the limits of experimental error.

Here it must be mentioned that wherever possible the collection of urine was done at the hospital. In a few cases the samples of urine were brought by the patients. The completeness of the collection of urine excreted in 24 hours will in future be checked by a determination of its creatinine content.

\section{COMMENTS}

From Table 2 it is evident that the 24-hour excretory pattern of DDS following an oral test dose varies within wide limits in different patients. Fairly consistent blood concentration curves of DDS could be obtained (Graph 1) co-relating to the excretory pattern.

In the case of patients excreting more than $70 \mathrm{mgm}$. in 24 hours (Graph 2) the peak concentration in the blood is reached 6 hours after administration of the drug, while in those excreting less than $30 \mathrm{mgm}$. it occurs at 8 hours. Though the maximum blood concentration is more in the case of the former there is a tendency for the concentration to drop down earlier during 24 hours than in the latter case. The implications of such a 24-hour study in patients receiving prolonged DDS treatment remains to be investigated. However it may be stated that the possibility of more sustained blood levels of

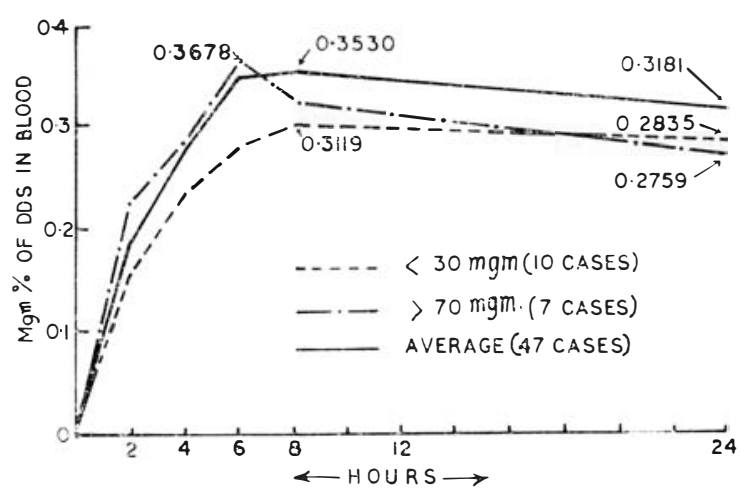

GRAPH 2

Showing blood concentration curves of patients excreting less than $30 \mathrm{mgm}$. and more than $70 \mathrm{mgm}$. of DDS.

IDS in patients who excrete IDD at a slow rate may account for prolonged tissue concentrations of the drug at high levels in such patients.

The figures in Table 3 point to an apparent consistency of the urinary excretion pattern in the same individual when re-tested at intervals of one month, 3 months, and 12 or 14 months.

The next question that arises is what correlation exists between the excretory pattern and reactions and improvement in leprosy patients under treatment with DDS.

Table 4 shows reactions in all types of patients (lepromatous, borderline, reactional, tuberculoid, tuberculoid major) in relation to their excretion rates.

The majority of patients with reaction are within the $30-55 \mathrm{mgm}$. excretion group. However, it has to be appreciated that the causes of reactions in leprosy are numerous and some of these reactions may have been due to causes other than DDS treatment.

An attempt was made to study the excretory pattern in patients under treatment when in reaction. It was found that although the usual treatment dose of DDS was stopped excretion of DDS continued in appreciable amounts for as long as the reaction persisted. This aspect is receiving close attention.

With regard to improvement in relation to the excretory pattern the improvement noted 
TABLE 4

Showing DDS excretion pattern in patients with reaction

\begin{tabular}{|c|c|c|c|c|c|}
\hline $\begin{array}{l}\text { Mgm. excreted } \\
\text { in } 24 \text { hours }\end{array}$ & Lepromatous & Borderline & $\begin{array}{l}\text { Reactional } \\
\text { Tuberculoid }\end{array}$ & Tubcrculoid & Total \\
\hline $10-20$ & 1 & - & - & - & 1 \\
\hline $20-30$ & 4 & - & - & - & 4 \\
\hline $30--35$ & 7 & - & 2 & 1 & 10 \\
\hline $35-40$ & 8 & 5 & 3 & 1 & 17 \\
\hline $40-45$ & 9 & 1 & 4 & - & 14 \\
\hline $45-50$ & 6 & 3 & 4 & 1 & 14 \\
\hline $50-55$ & 3 & 6 & 1 & 3 & 13 \\
\hline $55-60$ & 3 & 1 & 2 & - & 6 \\
\hline $60-70$ & 3 & - & - & 2 & 5 \\
\hline $70-80$ & 1 & 1 & 1 & - & 3 \\
\hline $80-90$ & 1 & - & 1 & - & 2 \\
\hline Total & 46 & 17 & 18 & 8 & 89 \\
\hline
\end{tabular}

in the registers against non-lepromatous patients is subject to human error as there is no yardstick to assess the improvement acurately. In lepromatous patients the number of bacilli is the criterion.

However, it must also be mentioned that a number of patients are given tablets of DDS reguarly but they do not take them regularly. Such patients will not show improvement, but they will be taken for assessment as receiving regular treatment. To give an example, the following may be quoted:-

G.S.R., male, aged 16 years in 1957 , noted as taking treatment for 65 months out of 108 months. The DDS estimation done in 1966 showed that he was taking tablets (he may have taken tablets a few days previously) yet there was no improvement. He was admitted as an inpatient and the taking of tablets was supervised. He showed bacteriological improvement.

To avoid all fallacies therefore, lepromatous patients rendered negative without reactions, should be taken for assessment and not patients who show only improvement. In the series of lepromatous patients studied only one such patient exists. This patient was rendered negative by treatment over a period of 10 years. $\mathrm{He}$ excreted $41.34 \mathrm{mgm}$. in 24 hours with the $100 \mathrm{mgm}$. DDS test dose.

Investigations are proceeding.
SUMMARY

This presentation focuses attention to the wide variations in the urinary excretory pattern of DDS in leprosy patients, the probable immutability of the pattern in individuals, and the apparent correlation of the excretory pattern with improvement and reactions.

In 200 patients studied excretions as low as $18.01 \mathrm{mgm}$. and as high as $86.07 \mathrm{mgm}$. were encountered during 24 hours following an oral test dose of $100 \mathrm{mgm}$. DDS.

The excretory pattern of individuals seemed to be constant on re-testing at intervals of 1,3 and 12 months.

The majority of reactions were noted in the 30 to $55 \mathrm{mgm}$. range of excretors. As the causes of reactions are multifarious the findings in reaction patients are not taken as a basis for standardizing slow, moderate or rapid excretors.

Due to paucity of bacteriologically negative lepromatous patients without reactions correlation between excretory rate and improvement could not be determined.

\section{REFERENCES}

1. PETtit, REES and RIDLEy (1966). Int. .J. Lepr., 34, 374-390.

2. SimPSON (1949). Int. .J. Lepr., 17, 208-210. 